\title{
PERFORMANCE OF A CAD SCHEME APPLIED TO IMAGES OBTAINED FROM MAMMOGRAPHIC FILM DIGITIZATION AND FULL-FIELD DIGITAL MAMMOGRAPHY (FFDM)
}

\author{
Michele Fúlvia Angelo \\ Professora do Departamento de Tecnologia da Universidade Estadual de Feira de Santana \\ (UEFS). Doutora em Engenharia Elétrica pela Escola de Engenharia de São Carlos - \\ EESC, Universidade de São Paulo (USP).mfangelo@ecomp.uefs.br \\ Homero Schiabel \\ Professor da Escola de Engenharia de São Carlos - EESC, Universidade de São Paulo \\ (USP). Doutor em Engenharia Elétrica pela Escola de Engenharia de São Carlos - EESC, \\ Universidade de São Paulo (USP). Doutor em Física pelo Instituto de Física de São Carlos \\ - IFSC, Universidade de São Paulo (USP). homero@sc.usp.br. \\ Ana Claudia Patrocinio \\ Professora da Faculdade de Engenharia Elétrica da Universidade Federal de Uberlândia \\ (UEFS). Doutora em Engenharia Elétrica pela Escola de Engenharia de São Carlos - \\ EESC, Universidade de São Paulo (USP). acpatroc@yahoo.com.br.
}

\begin{abstract}
This work has as purpose to compare the effects of a CAD scheme applied to digitized and direct digital mamograms sets. A routine designed to be applied to mammogram in DICOM standard was developed and a schema based on the Watershed Transform to masses detection was applied to 252 ROIs from 130 digitized mammograms, resulting in $92 \%$ of true positive and $10 \%$ of false positives. For clustered microcalcifications detection, another procedure was applied to 165 ROIs from 120 mammograms, resulting in $93 \%$ of true positive and $16 \%$ of false positive. By using the same procedures to 154 digital mammograms obtained from FFDM, the rates have shown a little decrease in the scheme performance: $89 \%$ of true positive and $16 \%$ of false positive for masses detection; $90 \%$ of true positive and $27 \%$ of false positive for clusters detection. Although the tests with digital mammograms have been carried with a smaller number of images and different cases compared to the digitized ones, including several dense breasts images, the results can be considered comparable, mainly for clustered microcalcifications detection with a difference of only $3 \%$ between the sensibility rates for the both images sets. Another important feature affecting these results is the contrast difference between the two images set. This implies the need of extensive investigations not only with a larger number of cases from FFDM but also on the parameters related to its image acquisition as well as to its corresponding processing.
\end{abstract}

KEYWORDS: Computer-Aided Diagnosis (CAD), Full-Field Digital Mammography (FFDM), Digital Imaging and Communications in Medicine (DICOM) 


\title{
DESEMPENHO DE UM ESQUEMA CAD APLICADO EM IMAGENS MAMOGRÁFICAS OBTIDAS DE MAMOGRAFIAS DIGITALIZADAS E MAMOGRAFIAS DIGITAIS
}

\begin{abstract}
RESUMO
Este trabalho tem como objetivo comparar os resultados de um esquema CAD aplicado em conjunto de mamografias digitalizadas e em um conjunto de mamografias obtidas de um mamógrafo digital. Para extrair as imagens do padrão DICOM, padrão utilizado pelos mamógrafos digitais, uma rotina computacional foi desenvolvida. Para a detecção de nódulos, um esquema baseado em Transforma Watershed foi aplicado a 252 regiões de interesse (ROIs) de 130 mamografias digitalizadas, resultando em 92\% de verdadeiro positivo e $10 \%$ de falsos positivos. Para a detecção de microcalcificações agrupadas, outro procedimento foi aplicado a 165 ROIs extraídas de 120 mamografias digitalizadas, resultando em $93 \%$ de verdadeiro positivo e $16 \%$ de falso positivo. Ao utilizar os mesmos procedimentos para 154 mamografias digitais obtidas a partir de um FFDM, as taxas mostraram uma diminuição pequena no desempenho: $89 \%$ do verdadeiro positivo e $16 \%$ de falso positivo para a detecção de nódulos, e $90 \%$ de verdadeiro positivo e $27 \%$ de falsos positivo para a deteç̧ão de clusters de microcalcificações. Embora os testes com mamografias digitais tenham sido realizados com um menor número de imagens e casos diferentes em comparação com os digitalizados, incluindo várias imagens de mamas densas, os resultados podem ser considerados comparáveis, principalmente para a detecção de clusters de microcalcificações com uma diferença de apenas 3\% entre as taxas de sensibilidade para as imagens dos dois conjuntos. Outra característica importante que afeta esses resultados é a diferença de contraste dos dois grupos de imagens analisados. Isto implica na necessidade de extensas investigações não só com um maior número de casos de mamografias digitais, mas também um estudo sobre os parâmetros relacionados a aquisição da imagem, bem como para o seu processamento.
\end{abstract}

PALAVRAS-CHAVE: Diagnóstico Auxiliado por Computador, Mamografia Digital, DICOM.

\section{PERFORMANCE OF A CAD SCHEME APPLIED TO IMAGES OBTAINED FROM MAMMOGRAPHIC FILM DIGITIZATION AND FULL- FIELD DIGITAL MAMMOGRAPHY (FFDM)}

\section{INTRODUCTION}

Breast cancer has been one of the most feared diseases among women all over the world and it has been considered one of the most important causes of women mortality rates in many countries. Mammography is still considered the most efficient examination aimed to breast cancer detection mainly in early stages, when the cure possibilities are high. However, microcalcifications - signal of particular interest for such early detection - are commonly a challenge in radiologists interpretation in this exam.

Aimed to aid in this hard task of evaluating structures of interest in mammography images viewing, several works have been developed in the field of Computer-Aided Detection (CAD), with purposes of aiding in detection of mammographic details, providing something like a "second opinion" to the radiologist [1]. Among the used techniques, a particular interest is given to those intended to detect and/or characterize 
microcalcifications [2-17], suspicious masses [18-29] besides to pre-processing techniques aiming to enhance the mammographic images contrast in order to better detect such structure [30-36].

In the last years, some works [3], [6], [16], [20], [22], [25], [27] intended to detect and classify masses and microcalcifications, together with pre-processing techniques [32], [33], [35] have been developed by our group, all of them applied to images obtained from mammographic film digitization. The recent introduction of the digital mammography systems - computed radiography (CR) technology or full-field digital mammography (FFDM) equipment - the attention has been changed to that called "direct digital" image, stored according the DICOM standard. Such type of digital image is obtained by conversion of X-rays intensity distribution to electronic signal (directly or by an indirect procedure which is intermediate by a conversion of X-rays in visible light - FFDM systems - or in charges scanned by a laser beam - most of CR systems) which is then converted to the digital format by a proper analog-digital converter (ADC) [37]. This procedure is quite different of the film digitization process, where firstly the X-rays intensity distribution is converted in optical density distribution on the film which is then scanned by a white light or laser source in order to transform the film darkness variations in gray scale variations in the digital image.

Due to these differences in digital image acquisition by the two processes, there could also be differences in the sensibility of the previous developed techniques when applied to images obtained by the direct digital procedure or by the indirect film digitization, as in the most of CAD schemes applications. Therefore, the aim of this work is performing tests with the previous implemented techniques designed to detect masses or microcalcifications in re-gions of interest (ROIs) selected from mammographic images in order to verify results ob-tained for direct digital and digitized mammograms and corresponding effects.

\section{MATERIALS AND METHODS}

Digital mammograms used in the tests were obtained from a GE Senographe 2000D equipment (FFDM type), without HTC grid, while mammograms from analog systems were digitized in a Lumiscan 75 digitizer (Lumisys, Inc., now Eastman Kodak), with 12 bits and $0.075 \mathrm{~mm}$ of contrast and spatial resolutions, respectively.

This work was divided in three stages: extraction of the image from the DICOM file (when applied), application of a scheme for microcalcifications detection and application of another procedure for nodules detection.

\section{A. DICOM file image extraction}

For processing the direct digital images, a procedure should be firstly developed in or-der to extract only the image from the DICOM file, saving it then only as an image file in TIFF format to be segmented by the proper techniques. Although many types of information are stored in a DICOM file [38], for this specific stage, only those related to the image information were of our interest.

The free software ezDICOM was then used for viewing the DICOM files. Its code was customized with purpose of not only opening the file but also extracting the image file and saving it in TIFF format. 


\section{B. Clustered microcalcifications detection}

The detection of clustered microcalcifications was possible by using a previous developed technique, named Hybrid [3]. This technique was implemented basically from a junction of three other techniques previously described in literature by Nishikawa et al. [39], Wallet et al. [40] and Nappi et al. [41].

\section{Nishikawa's technique [39]}

This method uses two filters (match filter) for suppressing the image background while increasing the microcalcifications intensity. Two matrixes were used in the implementation, a $3 \times 3$ pixels matrix, and another of $11 \times 11$ pixels. Both are applied to all image pixels so that the first multiplies the actual pixel by 0.75 and its connected-by- 8 neighborhood by 1.0; the values are summed and then divided by 9; then, the result is stored in the memory, while in the other matrix the pixels are multiplied by a factor of 0.125 , and summed. After this, a subtraction between both matrixes is performed. As consequence, the effect of background suppression is obtained and the microcalcifications are enhanced. Such a result is stored in a two-dimensional matrix.

A global threshold is used in this method: in the dynamic matrix with the result from the match filter all the pixels are verified and $98 \%$ of those with smallest intensity are eliminated. A morphological erosion is also used in order to verify all the dynamic matrix pixels and it eliminates signals which do not have at least 4 adjacent pixels in the connected-by-8 neighborhood of the pixel under study. In order to detect the microcalcifications, this method uses also a local threshold. A calculation based on the average of intensity and on the standard deviation (SD), calculated in a region centered in each pixel of a $25 \times 25$ pixels image, was implemented. Pixels with intensity value larger than the SD value are stored in a final result matrix, which has the same size of the original image; those with intensity value smaller than that are eliminated.

The Figure 1 represents a diagram corresponding to the Nishikawa's method for microcalcifications detection [39]. 


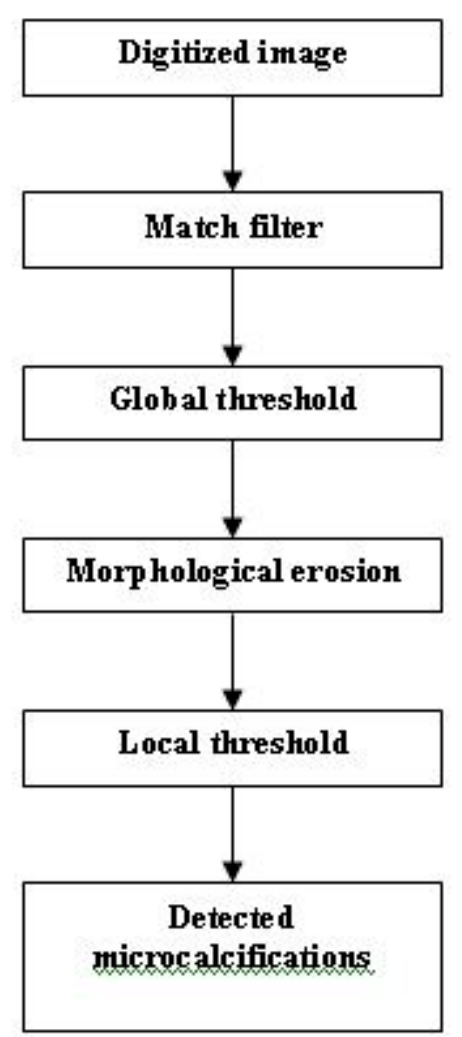

Figure 1 - Method for microcalcifications detection proposed by Nishikawa et al. [39].

\section{Wallet's technique [40]}

This method is based on the application of the high-boost filter, according to the following steps: firstly a matrix was created in the computer memory, with the same size of the matrix containing the original image; in such a matrix the value calculated for each pixel in the original image multiplied by 1.2 (the signal amplification value, obtained empirically by Wallet et al.[40]) is stored. After this multiplication, the difference between this value and the actual pixel low pass filter is calculated. This is performed by calculating, in the image matrix, the average of the connected-by- 8 neighborhood of the pixel under processing. At the end, this value is addressed to the pixel from the matrix created for its storage.

The signal threshold was obtained by calculating the average of microcalcifications intensity, and this value was subtracted from the average of intensity of pixels neighbor to the microcalcifications. Then, the standard deviation of the neighborhood of the pixel under study is calculated and this value is divided by the previous calculation above.

The Figure 2 presents a diagram with a scheme corresponding to the method for microcalcifications detection proposed by Wallet et al. [40]. 


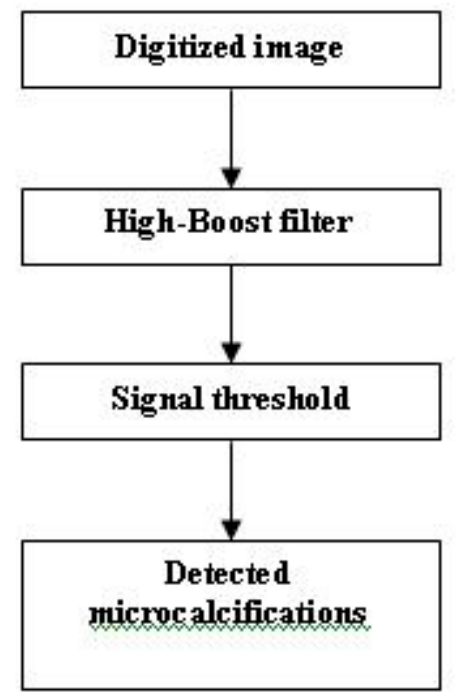

Figure 2 - Method for microcalcifications detection proposed by Wallet et al.[40].

\section{Nappi's technique [41]}

The method proposed by Nappi et al. [41] is characterized by removing the image background, which is provided by calculating the median filter, centered in each pixel of the dynamic matrix, and subtracting it from its respective pixel in the original image. Thus the image background is removed from the matrix and the pixels with intensity larger than their median remain in the final matrix.

The procedure for microcalcifications segmentation uses a local average centered in each pixel resulting from the previous process. The intensity of each pixel is calculated as well as the SD value. The pixels in the matrix with values smaller than that above are eliminated, remaining only the signals corresponding to microcalcifications. Figure 3 illustrates the diagram corresponding to this method [41].

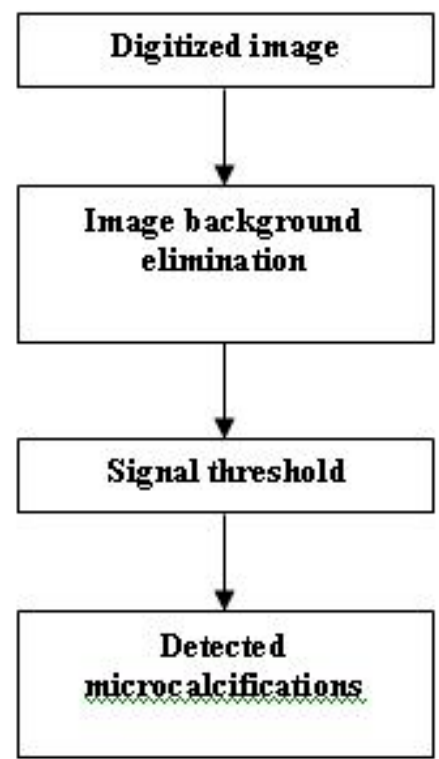

Figure 3 - Method for microcalcifications detection proposed by Nappi et al. [41]. 
Hybrid Technique

Based thus on the techniques summarized above, a Hybrid technique was implemented [3], joining them in a unique procedure (Figure 4). The main reason for this join was that, for many mammography images and ROIs, some of them missed microcalcifications which were however detected by other and vice-versa. Therefore, this new procedure has intended to link the results from each one so that one method complemented the others.

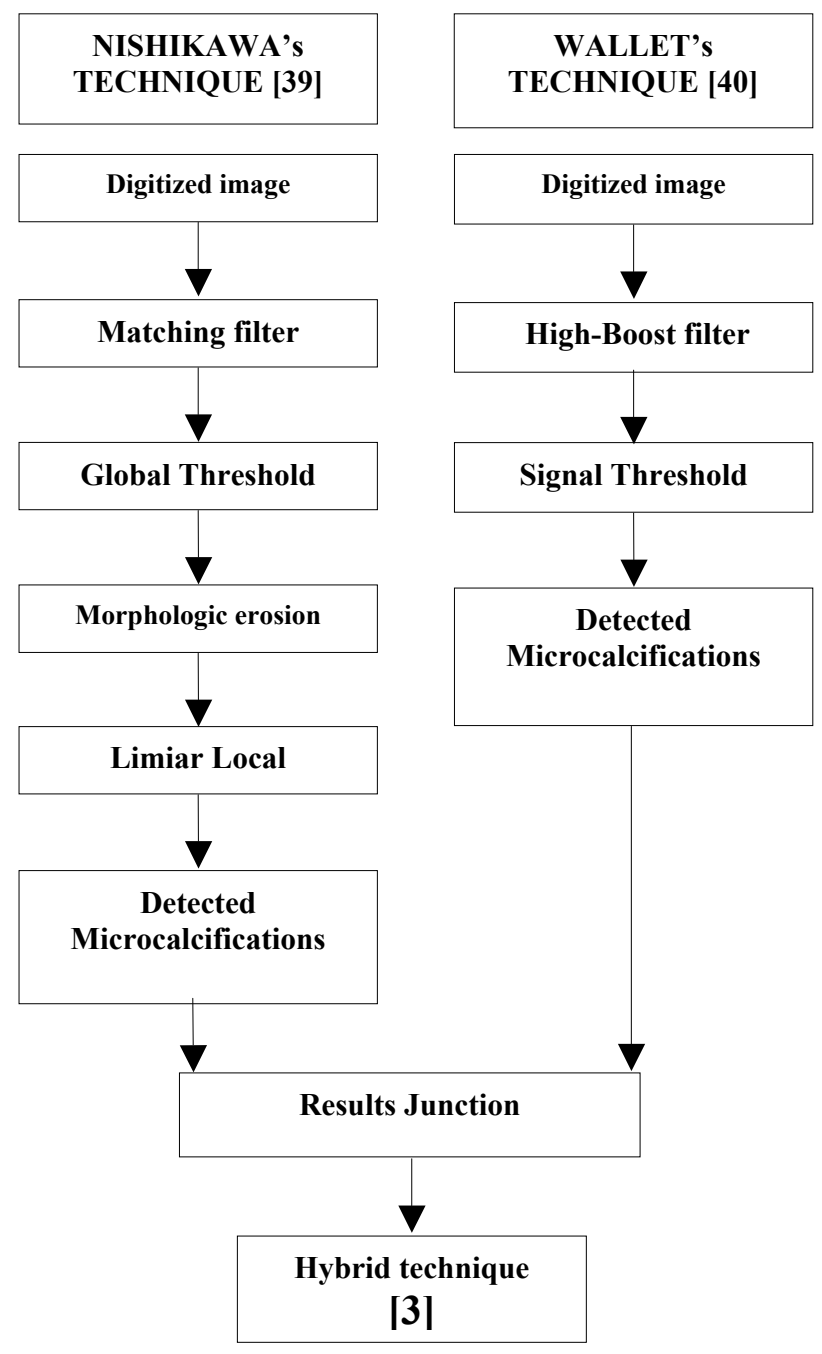

Figure 4 - Hybrid technique for microcalcifications detection [3].

\section{Masses detection}

Another previously segmentation technique developed in our group [22] was used aiming the suspicious masses detection in breast digitized images. Originally designed for dense breasts cases, where ROIs main characteristic is high density and hence poor contrast, a pre-processing technique was needed to be also implemented in order to improve the image contrast. A histogram equalization was used in this sense. After that, the segmentation was applied with basis on the Watershed Transformation [42], [43]. This transformation investigates the image histogram gray levels based on the principle that structures of interest correspond to a same frequency of such levels, being gradient and borders correspondent to high frequencies.

A post-processing step was needed in order to correct residual flaws. In such a step, the labeling technique - which addresses a unique tonality to the pixels of a same connected 
region - was applied. After that, the resulting image is aligned to the original one in gray scale with purpose of comparing the both images, enhancing the breast nodule. This complete scheme diagram is shown in Figure 5.

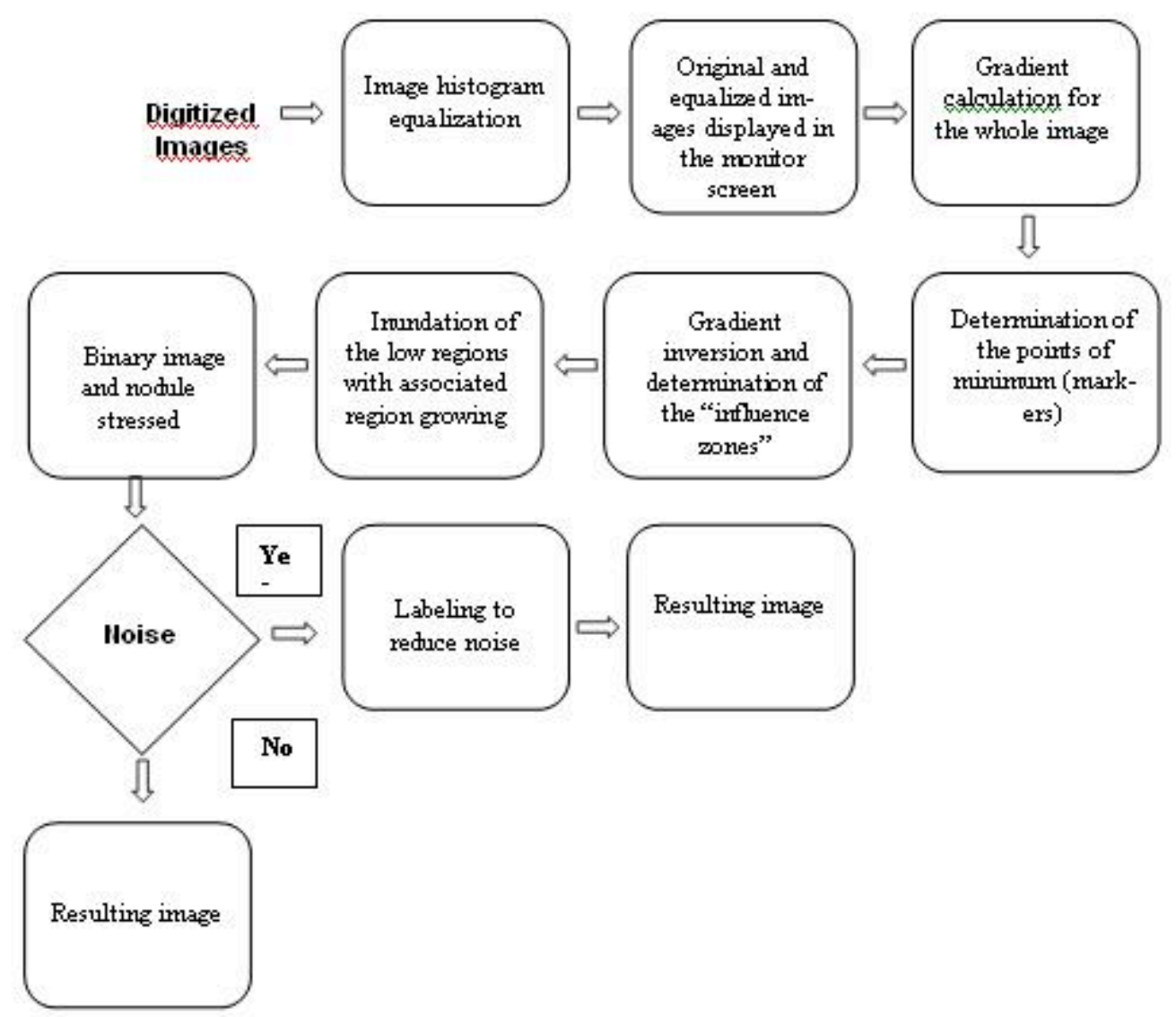

Figure 5 - Breast mass detection process: schematic diagram [22].

\section{RESULTS}

Initially tests were performed with images obtained from exposures in an analog and in a digital mammography equipment in order to check the changes needed in the segmentation schemes configurations. For adequate discrimination, we have determined the following convention: digitized mammogram will correspond to the mammographic digital image obtained after film digitization by a scanner, while direct digital mammogram will correspond to the image obtained from an analog-to-digital conversion of a signal formed by the X-rays photons interaction with an electronic sensor plate, as those existent in FFDM systems.

Results obtained from tests with the masses and microcalcifications detection schemes are presented by ROC curves methodology [44], [45], by the percentages of accuracy and by a statistical analysis in terms of sensibility and specificity - quantifying the true positive (TP), false positive (FP), true negative (TN) and false negative (FN) rates. From ROC curves, the schemes efficacy can be evaluated by the area under the curve (Az). High false negative rates indicate that the scheme is unable of detecting adequately many existent signals, that is, patients with lesions are missed. Also high false positive rates indicate that 
many cases reported as suspicious are indeed normal, which can lead many patients to unnecessary complementary exams.

Tests with digitized mammograms

A set of 130 digitized mammograms was used for testing the scheme intended to detect breast suspect masses and 120 were applied in evaluating the scheme for clustered microcalcifications detection. All mammograms were obtained from the archives of a public hospital (Hospital of Clinics in Botucatu/SP, of Medicine School, Paulista State University) - from Mammographic equipment Ge Senographe 600t Senix HF - and they were digitized by a Lumiscan laser digitizer (Lumisys, Inc.), with 12 bits and $0.075 \mathrm{~mm}$ of contrast and spatial resolution, respectively.

From the images set, 252 ROIs were selected in order to evaluate the masses detection (98 normal and 154 with masses, according to the radiologists reports). After processing all those ROIs by the previously described Watershed transform-based technique, the results have pointed about $92 \%$ of $\mathrm{TP}$ and $10 \%$ of $\mathrm{FP}$, considering a threshold of 3100 (corresponding to the value at the gray scale) set in the segmentation scheme. Table 1 details the results, which yielded a ROC curve, illustrated in Figure 6, with $\mathrm{Az}=0.910$.

Table 1 - Results from the masses detection scheme applied to 252 ROIs from digitized mammograms

\begin{tabular}{|c|c|c|c|c|c|c|c|c|}
\hline Threshold & TP & $\mathbf{( \% )}$ & FN & $(\mathbf{\%})$ & TN & $(\mathbf{\%})$ & FP & $(\mathbf{\%})$ \\
\hline 3100 & 142 & 92 & 12 & 8 & 88 & 90 & 10 & 10 \\
\hline
\end{tabular}

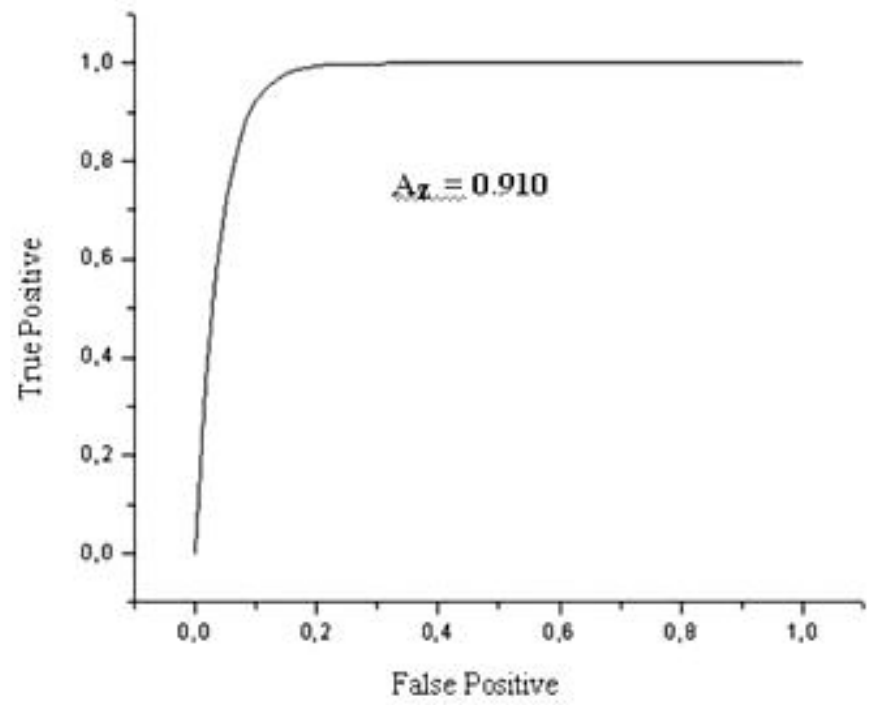

Figure 6: ROC curve corresponding to the tests performed with digitized mammograms for masses detection (data on Table 1).

For testing the microcalcifications detection scheme, a total of 165 ROIs were selected from the images set, being 63 normal and 102 with microcalcifications, according to the radiologists reports. After the processing, the results indicated $16 \%$ of false positive rate when using SD of 2.5 in the Nishikawa's technique [39] and 3.5 in the Wallet's one [40] in the Hybrid segmentation scheme [3], with about 93\% of accuracy, as shown in Table 2. Those SD values correspond to the choice yielding the best results. For this test, the corresponding ROC curve Az was 0.885, and it is illustrated in Figure 7. 
Table 2 - Results from the microcalcifications detection scheme (165 ROIs from digitized mammograms).

\begin{tabular}{|c|c|c|c|c|c|c|c|c|c|}
\hline \multicolumn{2}{|c|}{ Standard deviation } & TP & $\mathbf{( \% )}$ & FN & $\mathbf{( \% )}$ & TN & $(\mathbf{\%})$ & FP & $(\mathbf{\%})$ \\
\cline { 1 - 9 } Nishikawa & Wallet & \multirow{2}{*}{95} & 93 & 7 & 7 & 53 & 84 & 10 & 16 \\
\hline $\mathbf{2 , 5}$ & $\mathbf{3 , 5}$ & & & & & & & \\
\hline
\end{tabular}

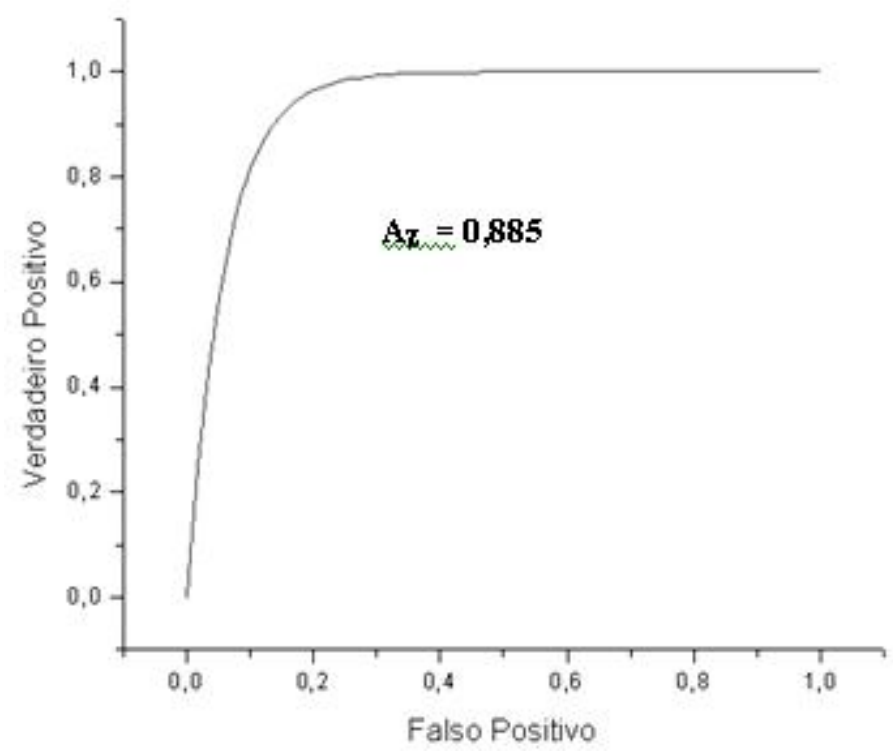

Figure 7: ROC curve corresponding to the tests performed with digitized mammograms for microcalcifications detection (data on Table 2).

\section{Tests with direct digital mammograms}

A set of 154 direct digital mammograms was also used for testing the schemes. They were obtained from exams performed with a GE FFDM system, model Senographe 2000D, installed at a private radiological clinic at S.Paulo/SP. For the tests with the masses detection scheme, 110 ROIs were processed -74 normal and 36 with masses according to the radiologists reports. The results have indicated $89 \%$ and $16 \%$ of true positive and false positive rates, respectively, using the same value of 3100 as the segmentation scheme threshold, as shown by Table 3. The area under the ROC curve for this case was 0.865 (Figure 8).

Table 3 - Results from the masses detection scheme applied to 110 ROIs from the direct digital mammograms set.

\begin{tabular}{|c|c|c|c|c|c|c|c|c|}
\hline Threshold & TP & $(\mathbf{\%})$ & FN & $(\mathbf{\%})$ & TN & $(\mathbf{( \% )}$ & FP & $\mathbf{( \% )}$ \\
\hline $\mathbf{3 1 0 0}$ & 32 & 89 & 4 & 11 & 62 & 84 & 12 & 16 \\
\hline
\end{tabular}




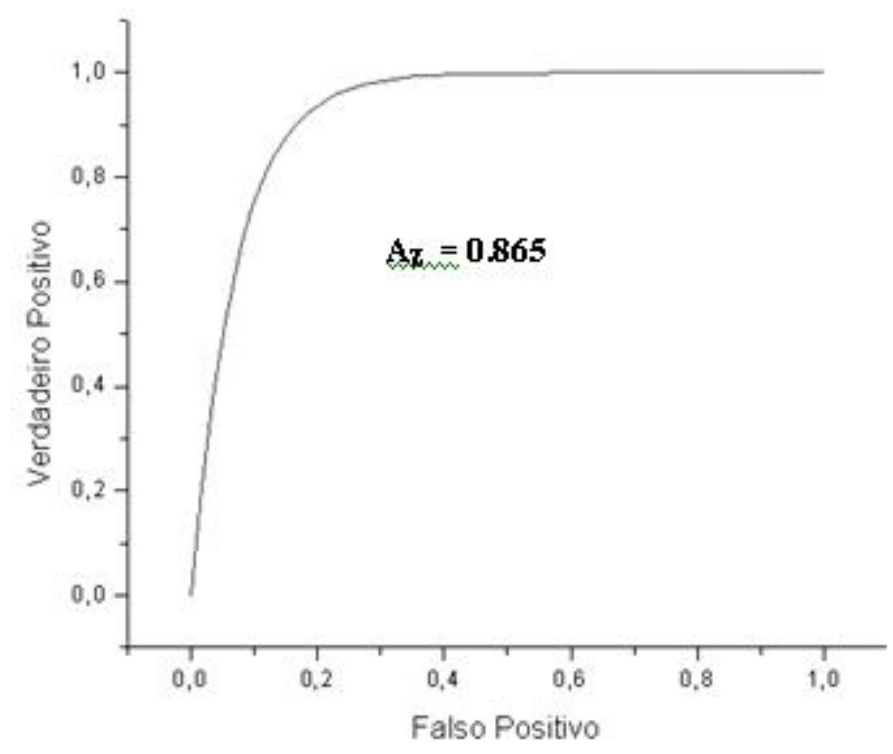

Figure 8: ROC curve corresponding to the tests performed with direct digital mammograms for masses detection (data on Table 3).

For testing the microcalcifications detection scheme, in the other hand, a total of 126 ROIs were selected from the images set, being 97 normal and 29 with microcalcifications, according to the radiologists reports. For such a test, the scheme has yielded the smallest false positive rate when using a SD of 3.5 for Nishikawa's technique [39] and 4.5 for the Wallet's one [40] in the Hybrid segmentation scheme [3]. The registered accuracy for this case was about $90 \%$, according to data in Table 4, with a ROC curve Az of 0.815 (Figure 9).

Table 4 - Results from the microcalcifications detection scheme (126 ROIs from direct digital mammograms set).

\begin{tabular}{|c|c|c|c|c|c|c|c|c|c|}
\hline \multicolumn{2}{|l|}{ Standard deviation } & \multirow{2}{*}{ TP } & (\%) & FN & (\%) & TN & (\%) & FP & (\%) \\
\cline { 1 - 10 } Nishikawa & Wallet & & & & & & & & \\
\hline $\mathbf{3 . 5}$ & $\mathbf{4 . 5}$ & 26 & 90 & 3 & 10 & 71 & 73 & 26 & 27 \\
\hline
\end{tabular}




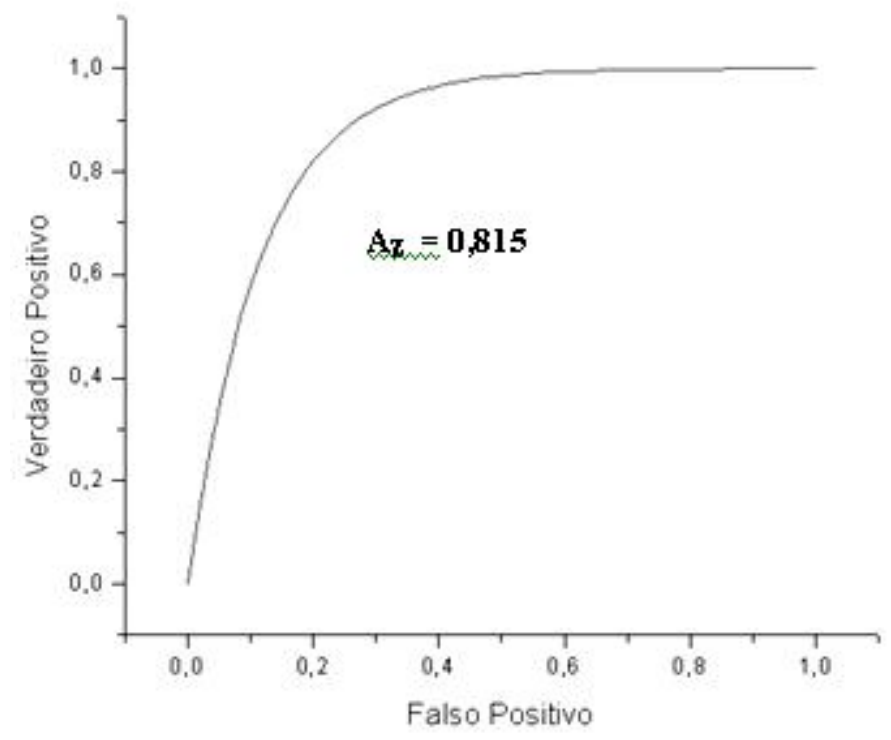

Figure 9: ROC curve corresponding to the tests performed with direct digital mammograms for microcalcifications detection (data on Table 4).

\section{DISCUSSIONS}

According to the results presented on Tables 1 and 3, the difference in the accuracy rates for masses detection was 3\% when compared the scheme performance for the both images sets: $92 \%$ with ROIs from the digitized mammograms, and $89 \%$ with ROIs from the direct digital mammograms. The false positive rate however has registered a larger variation, being $37.5 \%$ smaller for the digitized mammograms set than for the direct digital one $(10 \%$ against 16\%). This has implied a better $\mathrm{Az}$ in ROC curve analysis regarding the first images set, although only $5 \%$ larger $(0.910 \times 0.865)$.

The threshold value (3100) used for ROIs as from digitized mammograms as from the direct digital mammograms was that yielding the best results for masses segmentation regarding both images sets.

Relatively to microcalcifications detection, the results presented on Tables 2 and 4 have shown similar difference in the accuracy rates as for the masses segmentation - $93 \%$ with ROIs from digitized mammograms and 90\% with ROIs from the direct digital mammograms, both rates being significantly high. Nevertheless, again here the false positive rates comparison has registered a significant difference, and larger than for the masses segmentation: almost $41 \%$, with high FP rates $(16 \%$ for the digitized images set and $27 \%$ for the direct digital one). Also a larger difference in Az values was registered (about $8 \%$ higher for the tests with the digitized images set).

We should stress that those differences above were the smallest found in the tests, considering the possible variations for the SD value in the techniques implemented in the microcalcifications detection scheme. In searching for the more adequate SD values in the respective techniques, many tests were performed mainly for the direct digital images, in order to yield the results as closely as possible of those obtained with digitized mammograms. Obviously, the best cost-benefit ratio was taken into account in this evaluation, since as the SD values have been changed to reduce the FP, the sensibility has also been reduced. 


\section{CONCLUSIONS}

Although tests with direct digital mammograms have been performed with a smaller number of images - including a considerable number of dense breast cases - the results showed a good efficacy for the schemes performance, since the sensibility rates were high for both segmentation procedures and for both images sets, with an average difference about $3 \%$ in this last comparison.

An important feature justifying these differences in the detection rates between the two images sets (digitized and direct digital) can be the difference of contrast between them, in addition to the parameters used during the image acquisition $(\mathrm{kVp}, \mathrm{mAs})$ - operational mode - which have influence on the segmentation process. Another feature is that this new technology (FFDM systems) should be investigated more extensively besides an adequate and accurate calibration. For comparison, the digitizer used in this research was studied in details in order to be used in its maximum quality pattern [46]; However, the calibration and validation procedures for the technologies corresponding the FFDM system is not well defined yet, since it is recent.

\section{ACKNOWLEDGMENT}

The authors are grateful to CNPq, FAPESP and Hospital of Clinics in Botucatu/SP, of Medicine School, Paulista State University. Special thanks to Dr. Leandro F. Campos, who provided the images from a FFDM equipment for our analysis.

\section{REFERÊNCIAS BIBLIOGRÁFICAS}

1. GIGER, M.L. Computer-aided diagnosis of breast lesions in medical images. Computing in Science \& Engineering, v.2, p.39-45, 2000.

2. JIANG, Y., NISHIKAWA, R. M., PAPAIOANNOU, J. Requirement of microcalcification detection for computerized classification of malignant and benign clustered microcalcifications. Proceedings of SPIE International Symposium Medical Imaging - Image Processing, v.3338, p.313-317, 1998.

3. GOES, C.E., SCHIABEL, H., NUNES, F.L.S. Evaluation of microcalcifications segmentation techniques for dense breast digitized images. Journal of Digital Imaging, v.15 (suppl. 1), p.231-233, 2002.

4. CHENG, H.D., CAI, X., CHEN, X., HU, L., LOU, X. Computer-aided detection and classification of microcalcification in mammograms: a survey. Pattern Recognition, v.36, p.2937-2991, 2003.

5. KALLERGI, M. Computer-aided diagnosis of mammographic microcalcification clusters. Medical Physics, v.31, n.2, p.314-326, 2004.

6. PATROCINIO, A.C., SCHIABEL, H., ROMERO, R.A.F. Evaluation of Bayesian Network to classify clustered microcalcifications. Proceedings of SPIE - Medical Image 2004 - Image Processing. v.5370, p.1026-1033, 2004. 
7. PAPADOPOULOS, A., FOTIADIS, D.I., LIKAS, A. Characterization of clustered microcalcifications in digitized mammograms using neural networks and support vector machines. Artificial Intelligence in Medicine, v.34, p.141-150, 2005.

8. FU, J.C., LEE, S.K., WONG, S.T.C., YEH, J.Y., WANG, A.H., WU, H.K. Image segmentation feature selection and pattern classification for mammographic microcalcifications. Computerized Medical Imaging and Graphics, v.29, p.419-429, 2005.

9. YU, S., LI, K., HUANG, Y. Detection of microcalcifications in digital mammograms using wavelet filter and Markov random field model. Computerized Medical Imaging and Graphics, v.30, p.163-173, 2006.

10. JIANG, J., YAO, B., WASON, A.M. A genetic algorithm design for microcalcification detection and classification in digital mammograms. Computerized Medical Imaging and Graphics, v.31, p.49-61, 2007.

11. HALKIOTIS, S., BOTSIS, T., RANGOUSSI, M. Automatic detection of clustered microcalcifications in digital mammograms using mathematical morphology and neural networks. Signal Processing, v.87, p.1559-1568, 2007.

12. ARIKIDIS, S., KARAHALIOU, A., SKIADOPOULOS, S., KORFIATIS, P., LIKAKI, E., PANAYIOTAKIS, G., et al., Size-adapted segmentation of individual mammographic microcalcifications, Proceedings of the 8th IEEE international conference on bioinformatics and bioengineering, p.1-5, 2008.

13. WEI, L., YANG, Y., NISHIKAWA, R.M. Microcalcification classification assisted by content-based image retrieval for breast cancer diagnosis. Pattern Recognition, v.42, p.1126-1132, 2009.

14. ARIKIDIS, N.S., KARAHALIOU, N.S., SKIADOPOULOS, S., KORFIATIS, P., LIKAKI, E., PANAYIOTAKIS, G., COSTARIDOU, L. Size-adapted microcalcification segmentation in mammography utilizing scale-space signatures. Computerized Medical Imaging and Graphics, v.34, p.487-493, 2010.

15. MOHANALIN, J., BEENAMOL, P.K.K., NIRMAL, K. A novel automatic microcalcification detection technique using Tsallis entropy \& a type II fuzzy index. Computers and Mathematics with Applications, v.60, p.2426-2432, 2010.

16. SILVA JR, E.C., SCHIABEL, H., VENTURA, L.Detection of clusters of microcalcification based on associated differential and morfological filters in full mammogram. In: International Symposium on Medical Imaging, 2009, Orlando, FL, USA. Proceedings of SPIE - Medical Imaging 2009. Bellingham, Washingthon, USA, v.7259, p.72594G-1-72594G-10, 2009.

17. BALAKUMARAN, T., VENNILA, I.L.A., SHANKAR, C.G. Microcalcification Detection in Digital Mammograms using Novel Filter bank. Procedia Computer Science, v.2, p.272-282, 2010.

18. HADJIISKI, L., CHAN, H.P., SAHINER, B. et al. Improvement in radiologists' characterization of malignant and benign breast masses on serial mammograms with computer-aided diagnosis: an ROC study. Radiology, v.233, p.255-265, 2004.

19. VARELA, C., TIMP, S., KARSSEMEIJER, N. Use of border information in the classification of mammographic masses. Phys. Med. Biol., v.51, p.425-441, 2006. 
20. RIBEIRO, P.B. et al. Selection of the Best Features for the Classification of Contour of Mammary Nodules Using Artificial Neural Networks, Proceedings of Annual Meeting of the Society for Imaging Informatics in Medicine (SIIM), p.92-93, 2007.

21. PASQUALE, D., FANTACCI, M.E., KASAE, P., RETICO, A. Characterization of mammographic masses using a gradient-based segmentation algorithm and a neural classifier. Computers in Biology and Medicine, v.37, p.1479-1491, 2007.

22. SCHIABEL, H., SANTOS, V.T., ANGELO, M.F. Segmentation technique for detecting suspect masses in dense breast digitized images as a tool for mammography CAD schemes. Proceedings of the 23rd Annual ACM Synposium on Applied Computing, p.1333-1337, 2008.

23. DOMÍNGUEZ, A.R., NANDI, A.K. Detection of masses in mammograms via statistically based enhancement, multilevel-thresholding segmentation, and region selection. Computerized Medical Imaging and Graphics, v.32, p.304-315, 2008.

24. VELIKOVA, M., SAMULSKI, M., LUCAS, P.J., KARSSEMEIJER, N. Improved mammographic CAD performance using multi-view information: a Bayesian network frameworks. Phys. Med. Biol., v.54, n.5, p.1131-1147, 2009.

25. RIBEIRO, P.B., ROMERO, R.A.F., SCHIABEL, H. A fuzzy system for classification of breast masses. In: World Congress on Medical Physics and Biomedical Engineering 2009, IFMBE Proceedings. Berlim, Alemanha: Springer, v.25-IV, p.12381241, 2009.

26. SONG, E., XU, S., XU, X., ZENG, J., LAN, Y., ZHANG, S., HUNG, C. Hybrid Segmentation of Mass in Mammograms Using Template Matching and Dynamic Programming. Acad Radiol,v.17, p.1414-1424, 2010.

27. MENECHELLI, R.C., RIBEIRO, P.B., SCHIABEL, H. Classificação pela forma de nódulos mamográficos em imagens reais digitalizadas e simuladas. Anais do XXII Congresso Brasileiro de Engenharia Biomédica - SBEB, p. 717-720, 2010.

28. Buciu I, Gacsadi A. Directional features for automatic tumor classification of mammogram images. Biomedical Signal Processing and Control, v.6, n.4, p.370-378, 2011.

29. SAMPAIO, W.B., DINIZ, E.M., SILVA, A.C., PAIVA, A.C., GATTASS, M. Detection of masses in mammogram images using $\mathrm{CNN}$, geostatistic functions and SVM. Computers in Biology and Medicine, v.41, n.8, p.653-64, 2011.

30. JI, T.L., SUNDARESHAN, M.K., ROEHRIG, H. Adaptive image contrast enhancement based on human visual properties. IEEE Transactions on Medical Imaging, v.13, p.573-584, 1994.

31. CHENG, H.D., XU, H. A novel fuzzy logic approach to mammogram contrast enhancement. Information Sciences, v.148, p.167-184, 2002.

32. NUNES, F.L.S., SCHIABEL, H., BENATTI, R.H. Contrast enhancement in dense breast images using the modulation transfer function. Medical Physics, v.29, n.12, p.2925-2936, 2002.

33. VIEIRA, M.A.C., SCHIABEL, H., ESCARPINATI, M.C. Breast image quality enhancement by using optical transfer function and noise Wiener spectrum. Proceedings of 91st Scientific Assembly \& Annual Meeting of Radiological Society of North America (RSNA), p.702-702, 2005. 
34. SINGH, S., BOVIS, K. An evaluation of contrast enhancement techniques for mammographic breast masses. Information Technology in Biomedicine, IEEE Transactions, v.9, n.1, p.109-119, 2005.

35. NUNES, F.L.S., SCHIABEL, H., GOES, C.E. Contrast Enhancement in Dense Breast Images to Aid Clustered Microcalcifications Detection. Journal of Digital Imaging, v.20, n.1, p.:53-66, 2007.

36. PAPADOPOULOS, A., FOTIADIS, D.I., COSTARIDOU, L. Improvement of microcalcification cluster detection in mammography utilizing image enhancement techniques. Computers in Biology and Medicine, v.38, n.10, p.1045-1055, 2008.

37. PISANO, E.D., YAFFE, M.J. Digital Mammography. Radiology, v.234, p.353-362, 2005.

38. AMERICAN COLLEFE OF RADIOLOGY; NATIONAL ELECTRICAL MANUFACTURERS ASSOCIATIONS. Digital Imaging and Comunication in Medicine (DICOM): Version 3.0. Drafts Standard, ACR-NEMA Comitte, Working Group VI, Washington, DC., 1993.

39. NISHIKAWA, R.M., JIANG, Y., GIGER, M.L., DOI, K., VYBORNY, C.J., SCHMIDT, R.A. Computer-aided detection of clustered microcalcifications. Proceedings of IEEE International Conference on Systems, Man and Cybernetics, Chicago (USA), p.1375-1378, 1992.

40. WALlET, B.C., SOLKA, J.L., PRIEBE, C.E. A Method for Detecting Microcalcifications in Digital Mammograms. Journal of Digital Imaging, v.10, p.136139, 1997.

41. NAPPI, J., DEAN, P.B., NEVALAINEN, O., TOIKKANEN, S. Computerized diagnosis of breast calcifications using specimen radiography and simulated calcifications. Proceedings of SPIE Conference on Image Processing, v.3661, p.13511360, 1999.

42. BEUCHER, S., LANTUÉJOUL, C. Use of Watersheds in contour detection. Proc. International Workshop on Image Processing, Real-Time Edge and Motion Detection/Estimation, Rennes, 1979.

43. ROERDINK, J.B.T.M., MEIJSTER, A. The Watershed transform: Definitions, algorithms and parallelization strategies. Fundamenta Informaticae, v.41, p.187-228, 2000.

44. DOI, K. Overview on research and development of Computer-aided diagnostic schemes. Seminars in Ultrasound, CT and MRI, v.25, p.404-410, 2004.

45. GIGER, M.L. Computerized analysis of images in the detection and diagnosis of breast cancer. Seminars in Ultrasound, CT and MRI, v.25, p.411-418, 2004.

46. ESCARPINATI, M.C., VIEIRA, M.A.C., SCHIABEL, H. Computer Technique for Digital Radiographic Images Correction Based On The Characteristic Curve. Journal of Digital Imaging, v.15, p.228-230, 2002. 